Baião, IRS, Machado, LC, Souza, TD, Silva, JCVO \& Cotta, JAO (2020). Evaluation of a sanitary effluent treatment system by evapotranspiration. Research, Society and Development, 9(7): 1-18, e621974541.

\title{
Avaliação de um sistema de tratamento de efluente sanitário por evapotranspiração
} Evaluation of a sanitary effluent treatment system by evapotranspiration Evaluación de un sistema de tratamiento de efluentes sanitarios por evapotranspiración

Recebido: 15/05/2020 | Revisado: 15/05/2020 | Aceito: 20/05/2020 | Publicado: 29/05/2020

Isabela Ribeiro de Sousa Baião ORCID: https://orcid.org/0000-0002-3015-9595 Universidade do Estado de Minas Gerais, Brasil

E-mail: isabelarsbaiao@gmail.com

Larissa Costa Machado

ORCID: https://orcid.org/0000-0001-6226-3859 Universidade do Estado de Minas Gerais, Brasil E-mail: machadolarissac@gmail.com

Tamara Daiane de Souza

ORCID: https://orcid.org/0000-0002-6849-5877

Universidade Federal de Ouro Preto, Brasil

E-mail: tamaradaianesouza@gmail.com

Jaquelline Carla Valamiel de Oliveira e Silva

ORCID: https://orcid.org/0000-0002-8364-0366 Universidade do Estado de Minas Gerais, Brasil

E-mail: jackvalamiel@yahoo.com.br Jussara Aparecida de Oliveira Cotta

ORCID: https://orcid.org/0000-0001-6914-1176 Universidade do Estado de Minas Gerais, Brasil E-mail: jussara.cotta@uemg.br

\section{Resumo}

O Sistema de tratamento de efluente por evapotranspiração consiste em um método alternativo de tratamento do esgoto sanitário em que preponderam os processos de digestão anaeróbia e evapotranspiração. $\mathrm{O}$ presente trabalho tem como objetivo analisar o funcionamento de um tanque de evapotranspiração (TEvap) implantado no distrito de 
Bicuíba, no Município de Raul Soares-MG e avaliar seu custo-benefício. O estudo foi realizado em escala unifamiliar entre os meses de junho a outubro, durante os quais foram coletadas amostras uma vez por mês, totalizando cinco campanhas de coleta no local. Foram realizadas as seguintes análises para avaliar a fertilidade do solo: potencial hidrogeniônico, fósforo, nitrogênio, teor de umidade, substâncias húmicas, potássio, cálcio, magnésio, alumínio, acidez potencial $(\mathrm{H}+\mathrm{Al})$, fósforo remanescente (P-rem), matéria orgânica, micronutrientes ( $\mathrm{Fe}, \mathrm{Zn}, \mathrm{Mn}, \mathrm{Cu}$ ), boro e enxofre. Foram avaliados os custos de implantação, operação, manutenção, a influência do esgoto doméstico nas características do solo no sistema, bem como os principais cuidados envolvidos, de modo a obter uma análise do desempenho global do tanque de evapotranspiração em escala unifamiliar. Foi possível concluir que o TEvap é um sistema promissor para se implantar em zonas rurais brasileiras, pois apresenta um bom custo-benefício, uma vez que possibilita o tratamento de esgoto doméstico com baixo custo de implantação e manutenção, melhorando a qualidade de vida dos moradores da região e diminuindo os impactos ao meio ambiente.

Palavras chave: Efluente; Tratamento; Evapotranspiração; Solo; Fertilidade.

\section{Abstract}

The evapotranspiration effluent treatment system consists of an alternative method of sanitary sewage treatment in which the processes of anaerobic digestion and evapotranspiration preponderate. The objective of this work is to analyze the operation of an evapotranspiration tank (TEvap) in the district of Bicuíba, in the city of Raul Soares-MG, and to evaluate its cost-effectiveness. The study was carried out on a single-family scale between the months of June to October, during which samples were collected once a month, totaling five collection campaigns in the area. The following analyzes were carried out to evaluate soil fertility: potassium hydrogen nitrogen, phosphorus, nitrogen content, humic substances, potassium, calcium, Magnesium, aluminum, potential acidity $(\mathrm{H}+\mathrm{Al})$, remaining phosphorus (P-rem) Organic matter, Micronutrients (Fe, $\mathrm{Zn}, \mathrm{Mn}, \mathrm{Cu}$ ), Boron and Sulfur. The costs of implantation, operation, maintenance, domestic sewage influence on the soil characteristics in the system as well as the main care involved were evaluated in order to obtain an analysis of the overall performance of the evapotranspiration tank on a single family scale. It was possible to conclude that TEvap is a promising system to be implemented in rural areas of Brazil, since it offers a good cost-benefit, since it allows the treatment of domestic sewage with low implantation and maintenance costs, improving quality of the residents of the region and reducing the impacts of the environment. 
Keywords: Effluent; Treatment; Evapotranspiration; Ground; Fertility.

\section{Resumen}

El sistema de tratamiento de efluentes de evapotranspiración consiste en un método alternativo de tratamiento de aguas residuales en el que predominan los procesos de digestión anaerobia y evapotranspiración. El presente trabajo tiene como objetivo analizar el funcionamiento de un tanque de evapotranspiración (TEvap) implantado en el distrito de Bicuíba, en el municipio de Raul Soares-MG y evaluar su costo-beneficio. El estudio se realizó a escala unifamiliar entre los meses de junio a octubre, durante el cual se recolectaron muestras una vez al mes, totalizando cinco campañas de recolección en el sitio. Los siguientes análisis se llevaron a cabo para evaluar la fertilidad del suelo: hidrógeno potencial, fósforo, nitrógeno, contenido de humedad, sustancias húmicas, potasio, calcio, magnesio, aluminio, acidez potencial $(\mathrm{H}+\mathrm{Al})$, fósforo restante $(\mathrm{P}-\mathrm{rem})$, materia orgánica de micronutrientes $(\mathrm{Fe}$, $\mathrm{Zn}, \mathrm{Mn}, \mathrm{Cu}$ ), boro y azufre. Se evaluaron los costos de implantación, operación, mantenimiento, la influencia de las aguas residuales domésticas en las características del suelo en el sistema, así como las principales precauciones involucradas, con el fin de obtener un análisis del rendimiento general del tanque de evapotranspiración a escala unifamiliar. Fue posible concluir que TEvap es un sistema prometedor para ser implementado en áreas rurales brasileñas, ya que tiene una buena relación costo-beneficio, ya que permite el tratamiento de aguas residuales domésticas con bajo costo de implementación y mantenimiento, mejorando la calidad de vida de los residentes de la ciudad. ciudad región y reducir los impactos en el medio ambiente.

Palabras clave: Efluentes; Tratamiento; Evapotranspiración; Suelo; Fertilidad.

\section{Introdução}

Saneamento pode ser definido como um conjunto de medidas que visam preservar ou modificar as condições do meio ambiente com a finalidade de prevenir doenças, promover a saúde, melhorar a qualidade de vida da população e a produtividade do indivíduo, e facilitar a atividade econômica (BRASIL, 2015).

Dentre os componentes do saneamento básico, destaca-se o esgotamento sanitário, ainda muito precário no Brasil. Segundo dados do Sistema Nacional de Informações sobre Saneamento (SNIS) e do Instituto Trata Brasil, em 2018, apenas 53\% da população brasileira 
tinha acesso à coleta de esgoto e somente $46 \%$ dos esgotos coletados no país eram tratados (BRASIL, 2018).

Dessa forma, o lançamento de efluentes não tratados em cursos d'água é uma das principais causas de degradação de mananciais de água superficial no país e de proliferação de inúmeras doenças parasitárias e infecciosas. Torna-se, portanto, evidente a importância e a necessidade da realização de pesquisas relacionadas ao tratamento do esgoto domésticos em grande e pequena escala.

Os sistemas convencionais de coleta e tratamento de efluentes domésticos são inviáveis em zonas rurais, devido à maioria das residências estarem distante umas das outras. Tendo em vista esse fato, é importante uma leitura mais descentralizada do saneamento, adotando modelos que satisfaçam requisitos técnicos e econômicos observados além das fronteiras urbanas (Pires, 2012).

Segundo Von Sperling (1996), os aspectos mais importantes na seleção de sistemas de tratamento de esgotos são: eficiência, confiabilidade, disposição do lodo, requisitos de área, impactos ambientais, custos de operação, custos de implantação, sustentabilidade e simplicidade. Cada sistema deve ser analisado individualmente, adotando-se a melhor alternativa técnica e econômica. Os principais tipos de tratamento de esgoto em escala unifamiliar são: Fossa Negra, Tanque Séptico, Filtro Anaeróbico, Wetlands e Tanque de Evapotranspiração.

O Sistema de tratamento de efluente por evapotranspiração ou Tanque de Evapotranspiração (TEvap) consiste em um método alternativo de tratamento do esgoto sanitário em que preponderam os processos de digestão anaeróbia e de evapotranspiração. É constituído basicamente por um tanque impermeabilizado, dimensionado de acordo com a unidade domiciliar em questão, preenchido com camadas de diferentes materiais e plantado com vegetais que possuem uma alta demanda por água, como bananeira, mamoeiro, caeté e taioba. O TEvap é considerado um sistema fechado, ou seja, é projetado para que, em condições normais de funcionamento, não seja gerado nenhum tipo de efluente. Em caso de mau funcionamento ou sobrecarga, o efluente gerado pode ser direcionado para a rede de esgoto do município ou residência (Bernardes, 2014).

As vantagens da utilização de sistemas com plantas para tratamento de esgoto são: possibilidade de alta eficiência no tratamento em termos de ciclagem de nutrientes e degradação biológica da matéria orgânica, baixo custo de manutenção, consumo de energia mínima, relativa tolerância à variabilidade de carga, harmonia paisagística, redução da 
necessidade de utilização de fertilizantes, aplicação para tratamento terciário de efluentes de outros sistemas de tratamento e oportunidade de aplicação em comunidades ou residências.

O TEvap foi originalmente criado nos Estados Unidos pelo permacultor Tom Watson, com nome de Watson Wick e, posteriormente, adaptado e trazido ao Brasil por permacultores brasileiros (EMATER, 2020). Contudo, esse ainda não constitui um sistema amplamente estudado no país, principalmente no que diz respeito à parte de seu funcionamento. Um dos problemas encontrados é a falta de análise de seu custo-benefício, englobando avalição dos custos de implantação, de operação, de manutenção e desempenho do sistema, de modo a verificar a viabilidade econômica e ambiental. Adicionalmente, pouco se sabe em relação a possíveis problemas operacionais do sistema.

Diante do exposto, o presente trabalho tem como objetivo analisar o funcionamento de um tanque de evapotranspiração implantado no distrito de Bicuíba, no Município de Raul Soares-MG e avaliar seu custo-benefício.

\section{Metodologia}

Por se tratar de uma pesquisa que busca investigação e análise de um Tanque de Evapotranspiração, um sistema de tratamento de esgoto já instalado e em funcionamento em uma residência, este trabalho se enquadra como uma pesquisa de natureza básica, que objetiva gerar conhecimentos novos e úteis para o avanço da ciência sem aplicação prática prevista, que envolve verdades e interesses universais (Gerhardt \& Silveira, 2009).

Quanto à sua abordagem, esta pesquisa pode ser considerada quali-quantitativa, uma vez que ambas as perspectivas trabalham simultaneamente, de modo que possa propiciar uma interpretação mais ampla da realidade pesquisada (Giddens, 2012). Os estudos apresentados neste trabalho visam à avaliação de um sistema de tratamento de efluentes por evapotranspiração através de análises bibliográficas e laboratoriais. Quanto aos objetivos, esta pesquisa se enquadra como exploratória e descritiva, tendo a pesquisa exploratória como objetivo proporcionar maior familiaridade com o problema, com vistas a torná-lo mais explícito ou construir hipóteses (Gil, 2010). Já a pesquisa descritiva preocupa-se em descrever os fatos e fenômenos de determinada realidade, exigindo do investigador uma série de informações sobre o tema a ser pesquisado (Triviños, 1987).

Quanto aos procedimentos técnicos, esta investigação se enquadra como uma pesquisa bibliográfica e estudo de caso. A pesquisa bibliográfica parte do levantamento de teorias já analisadas, e publicadas por meios escritos e eletrônicos, como livros, artigos científicos, 
páginas de web site (Fonseca, 2002). O estudo de caso pode ser definido como um estudo de uma entidade bem definida, visando conhecer profundamente o como e o porquê de uma determinada situação que se supõe ser única em muitos aspectos, procurando descobrir o que há nela de mais essencial e característico (Fonseca, 2002).

Esta pesquisa tem como fundamentação teórica trabalhos e artigos científicos já publicados sobre o tema em estudo, além da legislação pertinente, por não se tratar de uma pesquisa inédita. A parte prática foi executada em um sistema de tratamento de efluente com características especificas, sendo utilizados microrganismos específicos.

\section{Material e Método}

Este trabalho objetivou a análise e avaliação de um sistema TEvap, implantado em uma residência rural desprovida de um sistema de esgotamento sanitário. $\mathrm{O}$ domicílio, localizado nas coordenadas latitude $20^{\circ} 4.925 ' \mathrm{~S}$ e longitude $42^{\circ} 21.354^{\prime} \mathrm{O}$, situa-se no Distrito de Bicuíba, na cidade de Raul Soares - MG, e possui um total de 4 moradores.

O sistema foi implantando na residência no ano de 2015, 2 anos antes da presente pesquisa, através de um programa municipal de saneamento rural. Com objetivo de se conhecer o processo de implantação do sistema, foi aplicado um questionário ao morador que acompanhou o procedimento de construção e uma avaliação in loco do sistema para determinar as dimensões, materiais utilizados, tempo de funcionamento, manutenções já realizadas, vazão de entrada, problemas observados e custos para construção.

$\mathrm{Na}$ implantação do TEvap em estudo, foram utilizadas mudas de bananeiras (Musa sp) e de taioba (Xanthosoma sagittifolium), em sua superfície. Atualmente, porém, apenas as bananeiras permanecem no local. As seguintes ações foram realizadas no decorrer da pesquisa: coleta de amostras de solo em diferentes pontos da superfície do Tanque de Evapotranspiração (foram escolhidos de forma uniforme), limpeza superficial do local retirando a vegetação e pedras, feita uma pequena cova de 5 a $10 \mathrm{~cm}$ de profundidade e um corte em uma das paredes da cova de 2 a $3 \mathrm{~cm}$ de espessura, e armazenamento do solo retirado.

Esse manejo foi realizado em todos os pontos, conforme a Figura 1. Em seguida, foi preparada uma amostra composta representativa para caracterização do solo. Foram realizadas cinco coletas, no período de junho a outubro, com um total de 6 amostras. As amostras de A1 a A5 são de solo retirado da superfície do TEvap e a amostra A6 foi coletada do entorno do sistema para comparação com as demais amostras (solo testemunha). 
Figura 1: Esquema simplificado dos pontos de coletada das amostras de solo.

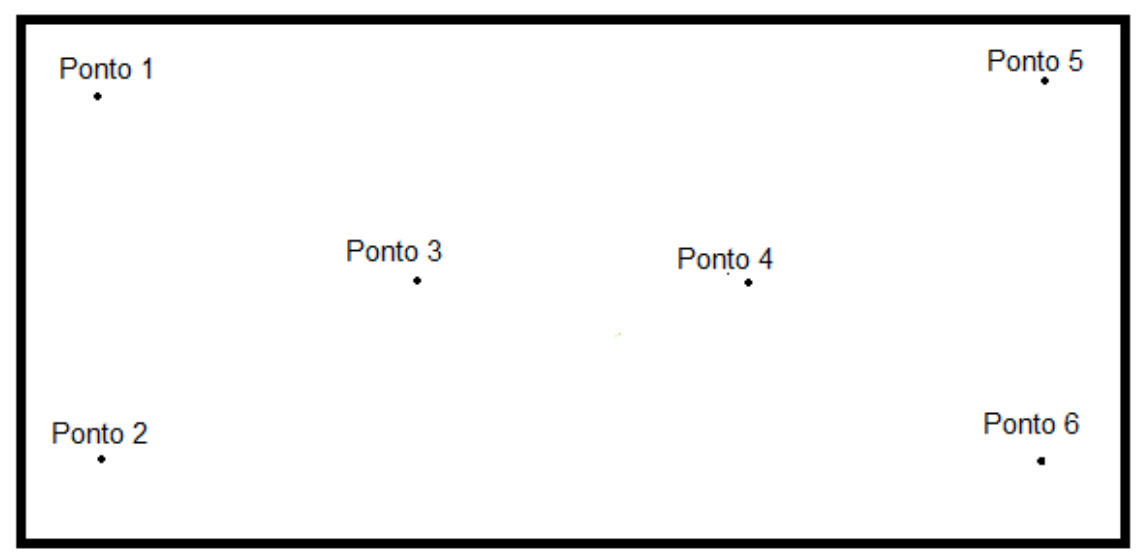

Fonte: Os autores (2019).

As amostras de solo coletadas foram enviadas ao Laboratório de Solos da Universidade Federal de Viçosa (UFV), onde foram realizadas as seguintes análises para avaliar a fertilidade do solo: potencial hidrogeniônico, fósforo, potássio, cálcio, magnésio, alumínio, acidez potencial $(\mathrm{H}+\mathrm{Al})$, fósforo remanescente (P-rem), matéria orgânica, micronutrientes (Fe, $\mathrm{Zn}, \mathrm{Mn}, \mathrm{Cu}$ ), boro e enxofre. Por sua vez, no Laboratório de Química da UEMG - Unidade João Monlevade, foram realizadas análises dos teores de nitrogênio total Kjeldahl (método Nessler), umidade e substâncias húmicas presentes nas amostras.

As análises para determinação de substâncias húmicas foram realizadas seguindo uma adaptação do método da Embrapa (Empresa Brasileira de Pesquisa Agropecuária) de Benites, Madari \& Machado (2003). As substâncias húmicas representam a matéria orgânica degradada no solo e se dividem em três frações, de acordo com os diferentes estágios de decomposição: ácidos húmicos, ácido fúlvicos e humina. Porém, o método empregado se concentrou em extrair apenas os ácidos húmicos. Os ácidos húmicos foram extraídos e purificados de acordo com a metodologia convencional estabelecida pela Sociedade Internacional para Substâncias Húmicas, baseada em solubilidade em solução alcalina de $\mathrm{NaOH} 0,1 \mathrm{~mol} \mathrm{~L}^{-1}$ e precipitação em ácido clorídrico $0,1 \mathrm{~mol} \mathrm{~L} \mathrm{~L}^{-1}$. Assim, foi realizada uma comparação dos valores obtidos nas análises do solo com os estabelecidos pela literatura, para se analisar a eficiência do sistema.

Em seguida, foram avaliados os custos de implantação, operação e manutenção do sistema, vida útil e desempenho global do tanque de evapotranspiração no que tange a custobenefício. 


\section{Resultados e Discussão}

Por meio do questionário aplicado, verificou-se que a família reside na propriedade desde o ano de 1991, e que no ano de 2015 foi implantado o sistema de tratamento de efluentes de evapotranspiração (Figura 2). Anteriormente à implantação do sistema, o esgoto era lançado em uma área de pasto, próxima a um pequeno lago, o qual não era submetido a qualquer forma de tratamento.

Foi possível verificar também que o sistema foi dimensionado para atender a uma família de cinco pessoas, porém, atualmente, apenas 1 pessoa reside no local durante a semana e 2 pessoas durante o final de semana. A implantação da TEvap foi subsidiada pela Prefeitura Municipal de Raul Soares, Minas Gerais, cabendo à referida família apenas a responsabilidade de ajudar a equipe contratada na construção. Com a implantação do sistema, a família relatou que houve melhoria nas condições de vida, uma vez que propiciou a eliminação de odor desagradável, da proliferação de mosquitos e impedimento da contaminação do solo e da água. A família considerou que o sistema atendeu às suas necessidades e, portanto, recomenda a implantação do TEvap nas demais residências da localidade.

Figura 2: Sistema de Tratamento de Efluente por Evapotranspiração.

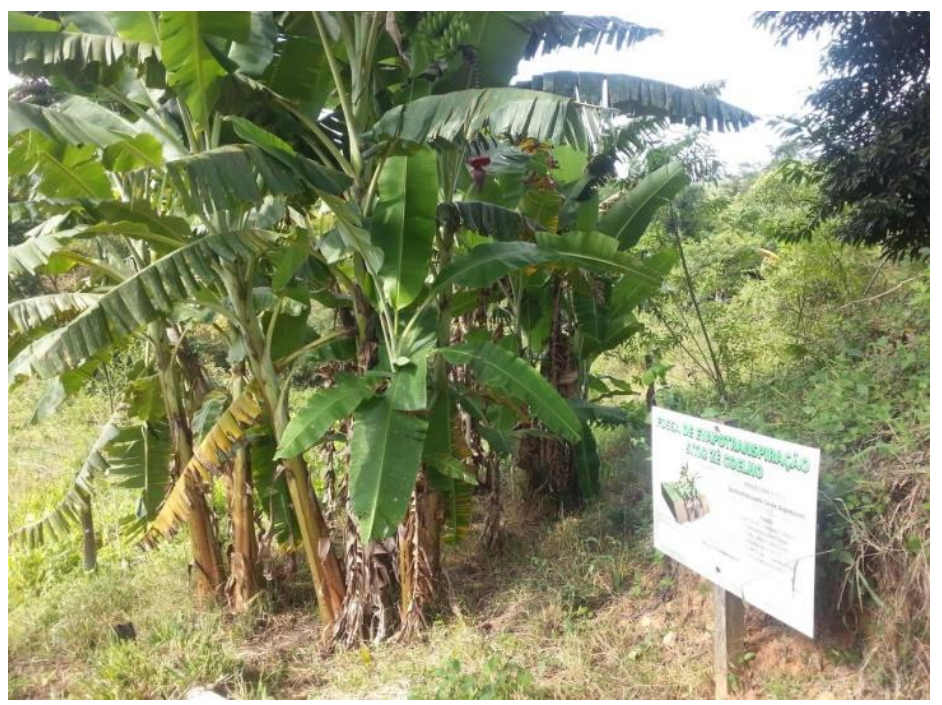

Fonte: Os autores (2019).

Quanto aos custos de implantação e manutenção do TEvap em relação ao sistema Fossa-Filtro, atualmente o mais utilizado e recomendado pela NBR 13969/1997 (ABNT, 1997), constatou-se que a implantação da TEvap é a fase que demanda o maior custo em todo 
o projeto, pois, em relação à manutenção, é necessário apenas o controle e a remoção da vegetação superficial. Além disso, esse sistema possui um maior tempo de vida útil do que o sistema Fossa-Filtro.

O Quadro 1 apresenta o orçamento realizado pela Secretaria Municipal de Meio Ambiente de Raul Soares, órgão responsável pela construção do TEvap, dos gastos estimados para a instalação do sistema.

Quadro 1: Custos de Implantação do Sistema de Tratamento de Esgoto por Evapotranspiração.

\begin{tabular}{|c|l|c|c|c|c|}
\hline Item & \multicolumn{1}{|c|}{ Material/Serviço } & Quantidade & Unidade & Preço Unitário & Total (R\$) \\
\hline 1 & Escavações Mecânicas - Retroescavadeira & 3,00 & Horas & 116,00 & 348,00 \\
\hline 2 & Brita & 1,00 & $\mathrm{~m}^{3}$ & 90,00 & 90,00 \\
\hline 3 & Areia & 1,00 & $\mathrm{~m}^{3}$ & 60,00 & 60,00 \\
\hline 4 & Cimento & 20,00 & Sacos & 22,00 & 440,00 \\
\hline 5 & Tela galinheiro & 24,00 & Metros & 12,00 & 288,00 \\
\hline 6 & Mão de obra (pedreiro) & 3,00 & Dias & 100 & 300,00 \\
\hline 7 & Mão de obra (ajudante) & 4,00 & Dias & 50,00 & 200,00 \\
\hline \multicolumn{4}{|c|}{ Total } \\
\hline
\end{tabular}

Fonte: Os autores (2019).

O efluente do vaso sanitário (água negra) entra pela parte inferior do tanque, permeando as camadas de material cerâmico e pedras, onde ocorre a digestão anaeróbia. Com o aumento do volume de esgoto no tanque, o conteúdo preenche também as camadas superiores, de brita e areia, até atingir a camada de solo que está acima, através da qual se move por capilaridade até a superfície. A água é eliminada do sistema através da evapotranspiração, enquanto que os nutrientes presentes são absorvidos pelas raízes e incorporados à biomassa das plantas.

No caso de sobrecarga, o efluente final, já parcialmente mineralizado, pode ser encaminhado para infiltração no solo ou para o sistema de coleta de esgoto, no caso de sistemas urbanos (Galbiati, 2009). O TEvap trata o esgoto doméstico de forma eficiente pelo fato de não gerar efluente excedente. Dessa forma, contribui para a melhoria da qualidade de vida dos moradores da residência onde foi implantado e até mesmo dos habitantes da região, pois colabora na prevenção de doenças infectocontagiosas. Além disso, diminui os impactos causados no meio ambiente, uma vez que reduz a contaminação do solo e da água.

Diante dos resultados obtidos, o TEvap apresenta um melhor custo benefício em relação aos demais sistemas, pois possui um baixo custo de implantação e manutenção, além de apresentar benefícios para o meio ambiente e para a saúde da população. 
Research, Society and Development, v. 9, n. 7, e621974541, 2020

(CC BY 4.0) | ISSN 2525-3409 | DOI: http://dx.doi.org/10.33448/rsd-v9i7.4541

Observou-se que não ocorreu nenhuma geração de efluente, sendo que o fator que contribuiu para isto é a subutilização do sistema, já que foi dimensionado para 5 pessoas e apenas uma pessoa reside no local na maior parte do tempo, somado ao fato das camadas já estarem compactadas, uma vez que o sistema já funciona há 2 anos. Assim, diante da condição de campo, realizou-se a coleta e a caracterização do solo do sistema.

Os resultados das análises de solo encontram-se nos gráficos de 1 a $6 . \mathrm{O}$ pH é um índice que fornece o grau de acidez ou alcalinidade de um extrato aquoso do solo. Trata-se de um índice que no caso de solos é utilizado como indicativo das condições gerais de fertilidade do solo. Segundo informações fornecidas pelo laboratório, o $\mathrm{pH}$ das amostras de solo foi medido em água e em uma proporção de 1:2,5 (Gráfico 1).

Gráfico 1: pH nos solos.

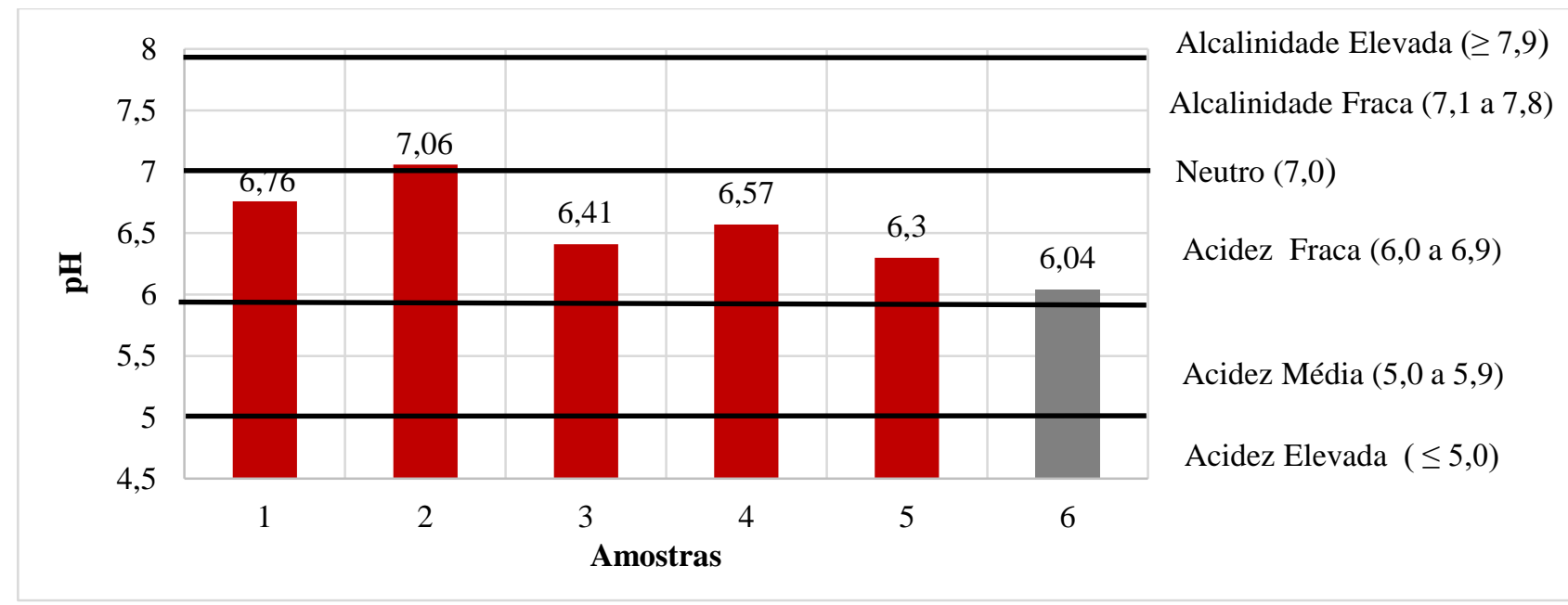

Fonte: Os autores (2019).

De acordo com Tomé Júnior (1997), o solo apresenta características de acidez fraca. O solo testemunho (A6), apesar de ser classificado como acidez fraca, apresenta um valor de $\mathrm{pH}$ mais próximo à acidez média do que as amostras coletadas na superfície do TEvap. Ainda segundo Tomé Júnior (1997), por apresentar valor de pH no intervalo de 5,0 a 7,0, esse solo não apresenta elevada acidez ou alcalinidade, podendo ser considerado um bom solo para cultivo.

Os resultados da concentração de potássio, fósforo e nitrogênio estão representados nos Gráficos 2 e 3. 
Research, Society and Development, v. 9, n. 7, e621974541, 2020

(CC BY 4.0) | ISSN 2525-3409 | DOI: http://dx.doi.org/10.33448/rsd-v9i7.4541

Gráfico 2: Concentração de fósforo e potássio $\left(\mathrm{mg}^{\mathrm{d}} \mathrm{dm}^{-3}\right)$.

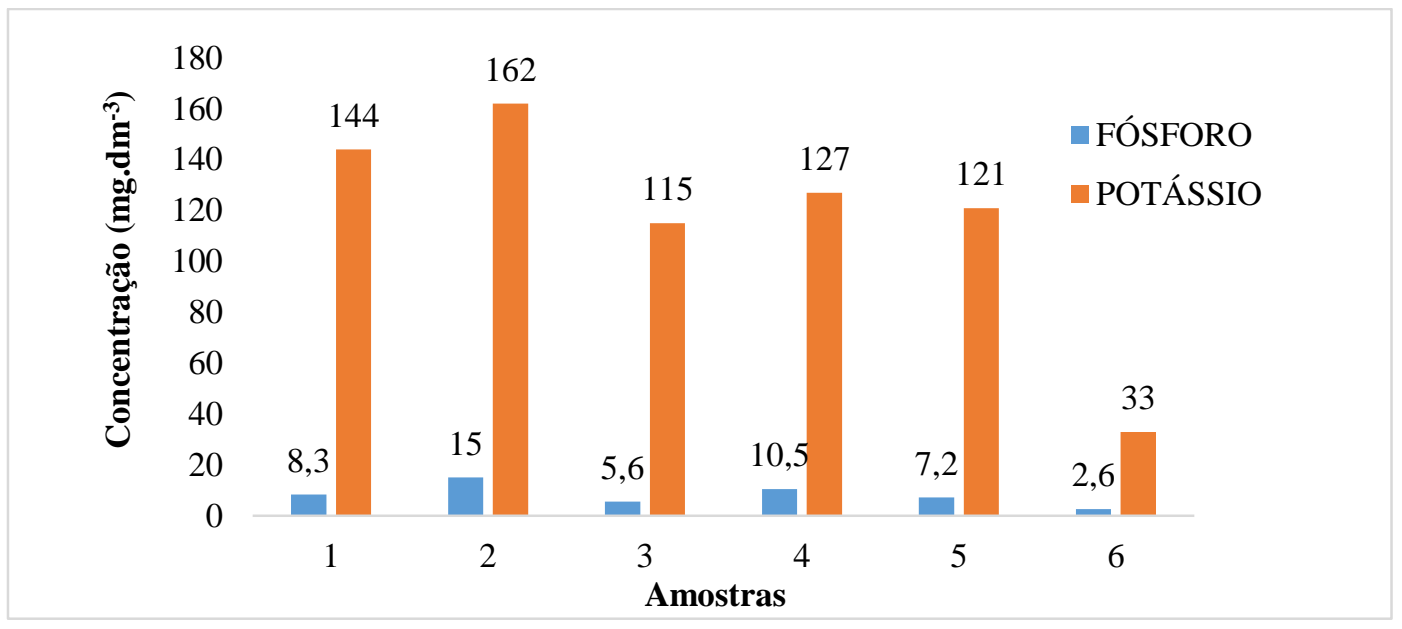

Fonte: Os autores (2019).

Gráfico 3: Concentração de nitrogênio (dag. $\left.\mathrm{kg}^{-1}\right)$.

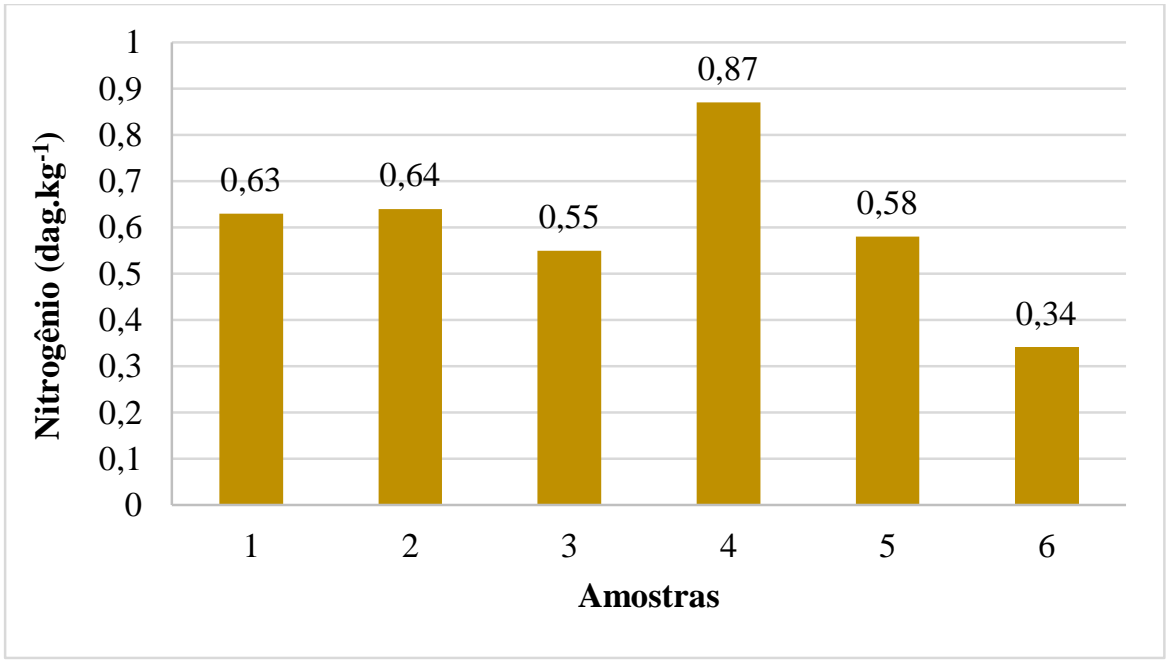

Fonte: Os autores (2019).

Os Gráficos 2 e 3 mostram um expressivo aumento da concentração desses macronutrientes no solo presente no sistema em relação ao solo testemunho. Quanto à quantidade de potássio, o solo do TEvap das amostras A1 a A5 é classificado como de teor alto, tendo uma concentração média de $133,8 \pm 19,12 \mathrm{mg} \cdot \mathrm{dm}^{-3}$, ou seja, maior que $80 \mathrm{mg} \cdot \mathrm{dm}^{-3}$ e o solo testemunho é considerado de teor baixo, por apresentar uma concentração entre 0 e $45 \mathrm{mg} \cdot \mathrm{dm}^{-3}$ (Tomé Júnior, 1997). A elevação do teor de potássio nas amostras de solo coletadas na superfície do sistema pode ser em decorrência do esgoto lançado no sistema, que ascende à superfície por capilaridade. Tal fenômeno é extremamente benéfico para um 
sistema de tratamento cultivado, pois sabe-se que a demanda por potássio nas culturas é grande, principalmente de bananeiras. Outra possibilidade que pode incrementar o teor de $\mathrm{K}$ no solo é o aporte de bananas no mesmo, uma vez que esta é uma fruta rica em potássio. Todavia, como é algo esporádico, uma vez que os moradores da residência realizam a colheita das bananas, acredita-se que a primeira hipótese seja mais coerente.

De maneira análoga, o nitrogênio e o fósforo estão presentes em excretas humanas e se ascendem por capilaridade para a superfície do sistema. Por esse fato, A1 a A5 possuem maior concentração desses nutrientes em relação ao solo testemunho. Em relação a A1 a A5, a concentração média de fósforo é de 9,32 $\pm 3,64 \mathrm{mg} \cdot \mathrm{dm}^{-3}$. Por sua vez, o nitrogênio apresentou uma concentração média de $0,65 \pm 0,13$ dag. $\mathrm{kg}^{-1}$. Isso representou um aumento de $258 \%$ de fósforo e $91 \%$ de nitrogênio em relação ao solo testemunha. Tendo em vista esses resultados, conclui-se que o TEvap está elevando a concentração dos macronutrientes no solo e melhorando a sua fertilidade, uma vez que esses elementos são de suma importância para o desenvolvimento das plantas. Essa dinâmica está de acordo com os princípios da sustentabilidade, tornando o processo cíclico e retornando os nutrientes para onde foram extraídos, o solo.

Conforme os resultados para os micronutrientes, percebe-se que a concentração de boro, cobre, zinco, ferro e manganês para as amostras A1 a A5 não apresentou variações significativas em relação ao solo testemunho. Isso ocorreu, pois esses nutrientes não são verificados em elevados teores no esgoto doméstico. Por esse fato, conclui-se que o sistema TEvap não influenciou nesses elementos.

Os resultados referentes à saturação por bases (SB) das amostras de solo estão representados no Gráfico 4.

Gráfico 4: Saturação por bases (\%).

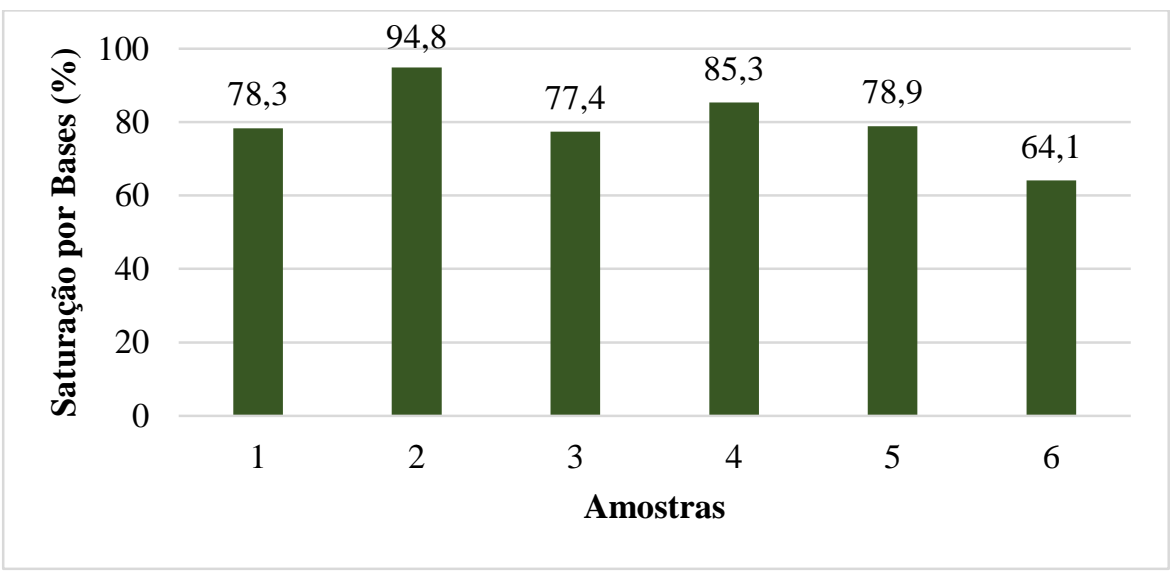

Fonte: Os autores (2019). 
A Saturação de Bases (SB) é resultado das somas dos teores de $\mathrm{Ca}, \mathrm{Mg}$ e K no solo. A SB média das amostras de 1 a 5 é de $82,94 \pm 7,33 \%$. O aumento de $29 \%$ da SB na média das amostras A1 a A5 em relação ao solo testemunho é por influência da alta concentração de K no solo do sistema. Por essas amostras apresentarem a Saturação por Bases maior que 50\%, o solo é classificado como Solo Eutrófico, sendo assim considerado fértil (Tomé Júnior, 1997).

O teor de matéria orgânica presente nas amostras de solo está representada no Gráfico 5.

Gráfico 5: Matéria orgânica $\left(\mathrm{g} \cdot \mathrm{dm}^{-3}\right)$.

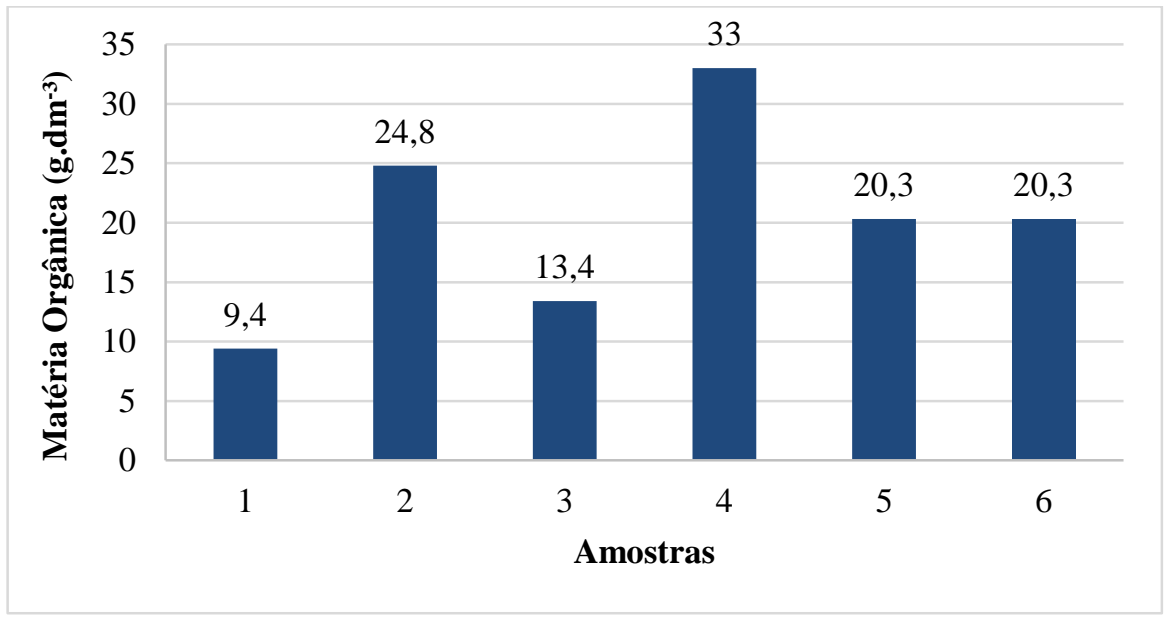

Fonte: Os autores (2019).

O teor da matéria orgânica nas amostras A1 a A5 não apresentou diferença expressiva em relação ao solo testemunho, pelo fato da mesma ficar retida na parte inferior do TEvap e não ascender, por capilaridade, para a superfície do sistema. A média de concentração da matéria orgânica foi de 20,18 \pm 9,33 g. $\mathrm{dm}^{-3}$. Considerando Tomé Júnior (1997), as amostras A1 e A3 são consideradas de baixo teor de matéria orgânica, pois suas concentrações estão abaixo de $15 \mathrm{~g} \cdot \mathrm{dm}^{-3}$. E as demais amostras são de teor médio, pois suas concentrações estão entre 15 e 50 g.dm ${ }^{-3}$. Esse resultado é benéfico para o sistema, pois significa que a matéria orgânica está sendo mineralizada pelos microrganismos, ou seja, convertida em $\mathrm{CO}_{2}$, o que aumenta a expectativa de vida útil do sistema.

Os teores de umidade (\%) nas amostras de solo estão representados no Gráfico 6. 
Gráfico 6: Teor de umidade (\%)

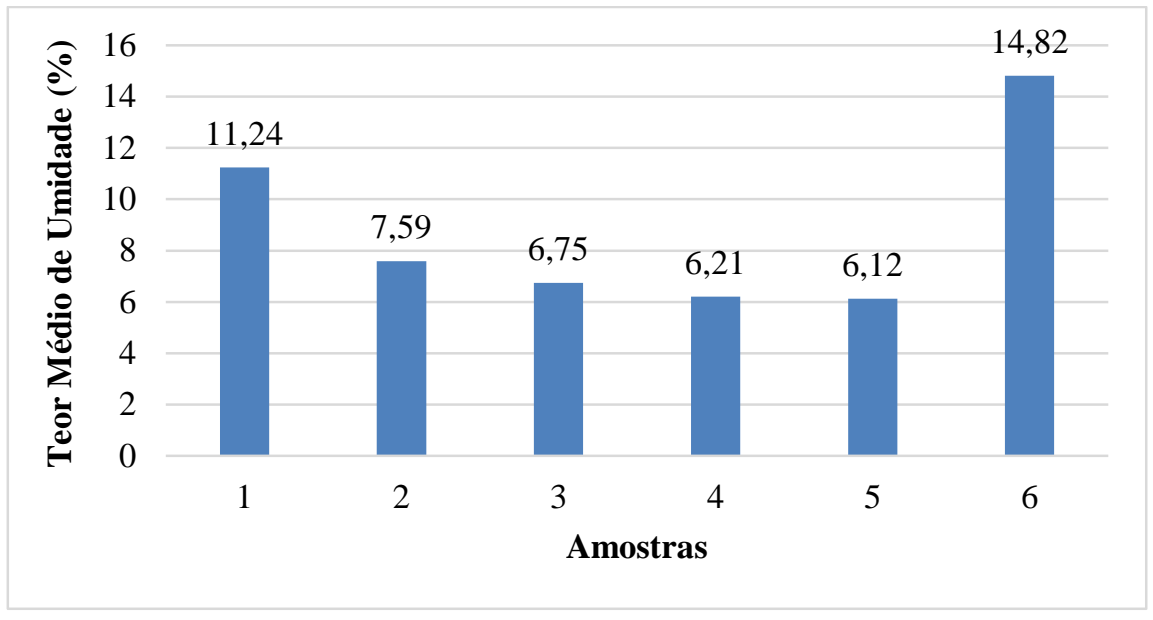

Fonte: Os autores (2019).

Foi possível verificar que a amostra A6 apresentou elevado teor de umidade devido à proximidade do ponto de coleta com um pequeno lago artificial e uma área alagada (brejo), conforme demonstrado na Figura 3.

Figura 3: Área alagada próximo e lago artificial próximo ao ponto de coleta 6.
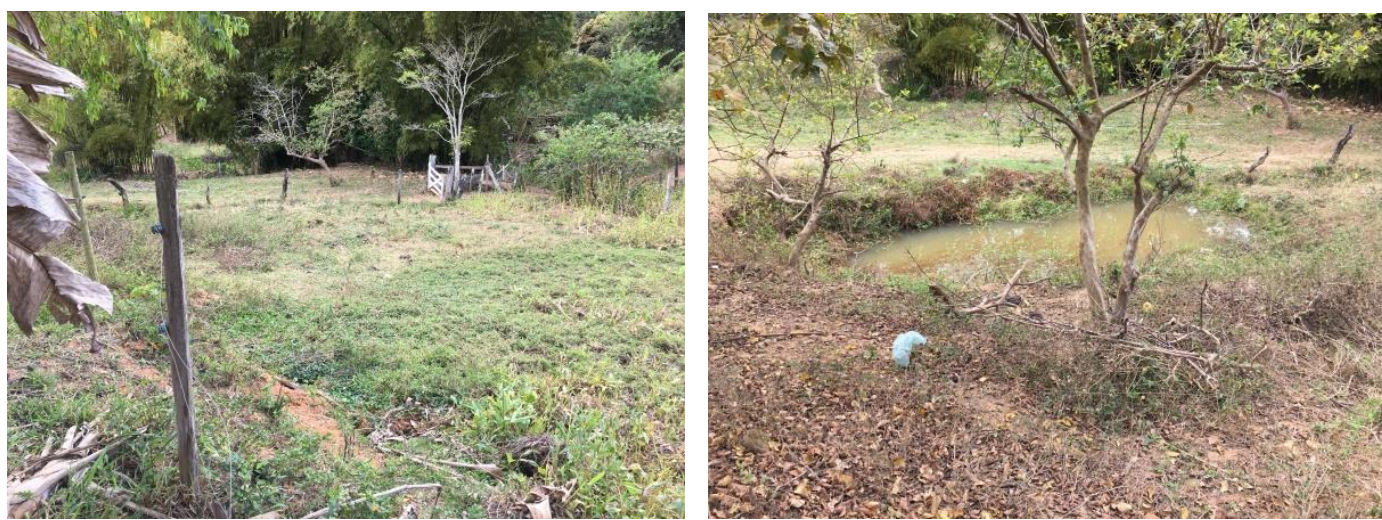

Fonte: Os autores (2019).

Os ácidos húmicos são responsáveis por aumentar a absorção de nutrientes, melhorar a estrutura do solo, com efeitos diretos na produção, produtividade e qualidade de diversos cultivos (Silva Filho \& Silva, 2002). Uma campanha de coleta para a extração do ácido húmico foi realizada, em diferentes profundidades (0-10, 10-20 e 20-30 cm). O teor de ácido húmico (\%) nas amostras coletadas em três diferentes profundidades do solo sobre o TEvap é representado no Gráfico 7. 
Gráfico 7: Teor de ácido húmico (\%) no solo.

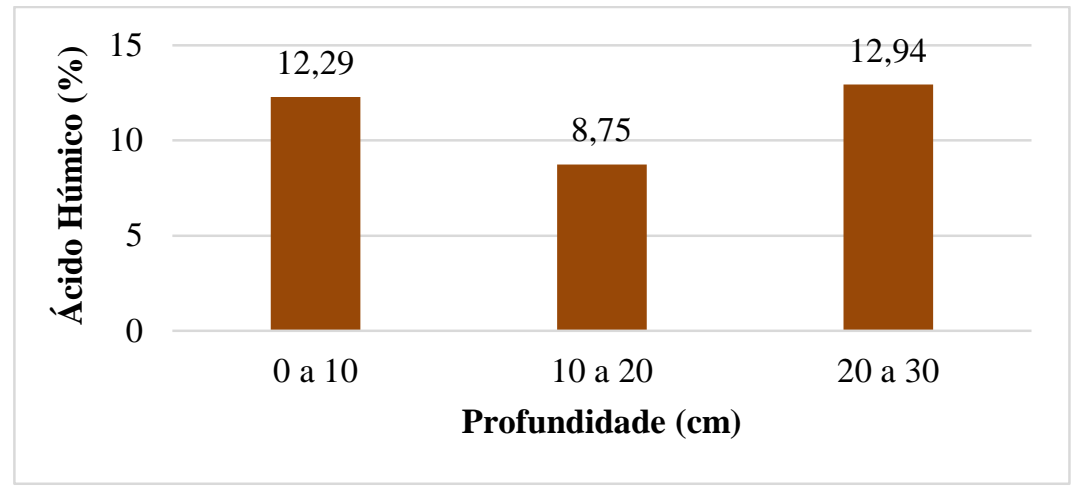

Fonte: Os autores (2019).

Nota-se que a amostra mais superficial $(0$ a $10 \mathrm{~cm})$ apresentou um teor médio alto de ácidos húmicos. Isso se deve à presença de matéria orgânica decomposta advinda de vegetação rasteira. A amostra intermediária $(10$ a $20 \mathrm{~cm})$ apresentou o mais baixo teor de ácidos húmicos, pelo fato de não ter contato direto com a vegetação rasteira ou com a matéria orgânica retida na parte inferior do TEvap.

Por sua vez, a amostra em maior profundidade (20 a $30 \mathrm{~cm})$ apresentou um maior teor de ácidos húmicos devido à contribuição do esgoto lançado no TEvap. No estudo realizado por Canellas, Santos, Rumjanek, Moraes \& Guridi (2001), a distribuição da matéria orgânica e as características de ácidos húmicos em solos com adição de resíduos de origem urbana, foram encontradas as frações humificadas da matéria orgânica em amostras de dois solos (Latossolo Vermelho-Amarelo e Argissolo Vermelho-Amarelo), aos quais foram adicionados lodo de uma estação de tratamento de esgoto.

Os resultados encontrados pelos autores (2001) nas amostras de solo com adição de lodo foram de 1,7 g. $\mathrm{kg}^{-1}$ de ácidos húmicos no latossolo vermelho-amarelo e de $0,7 \mathrm{~g} . \mathrm{kg}^{-1} \mathrm{de}$ ácidos húmicos no argissolo vermelho-amarelo, valores expressivamente abaixo dos encontrados neste estudo.

\section{Considerações Finais}

Ao final desse estudo foi possível concluir que o Sistema de Tratamento de Efluentes por Evapotranspiração é um sistema promissor para se implantar em zonas rurais brasileiras, pois apresenta um bom custo-benefício, uma vez que possibilita o tratamento de esgoto doméstico com baixo custo de implantação e manutenção, melhorando a qualidade de vida dos moradores da região e diminuindo os impactos ao meio ambiente. 
Pode-se inferir que o sistema pode ser utilizado para o cultivo de espécies com elevadas exigências nutricionais, além de propiciar aumento da fertilidade do solo em sua superfície, com elevadas concentrações de macro e micronutrientes necessários para o desenvolvimento de algumas espécies de plantas, como a bananeira.

Os baixos teores de matéria orgânica do sistema indicam que há elevada taxa de mineralização da mesma, e que se encontra, em sua maioria, na parte inferior do tanque. Com esse resultado, existe a expectativa que o sistema tenha elevada vida útil sem necessitar de troca do meio suporte, sendo este intervalo possivelmente superior quando comparado aos sistemas convencionais, como o taque séptico e filtro anaeróbio.

Portanto, diante dos resultados, pode-se dizer que o sistema de tratamento de efluentes por evapotranspiração é uma alternativa viável, sustentável e que deve ser amplamente difundida nas zonas rurais, nas quais não há rede de coleta e tratamento do esgoto.

\section{Referências}

ABNT - Associação Brasileira de Normas Técnicas (1997). NBR 13969 - Tanques sépticos Unidades de tratamento complementar e disposição final dos efluentes líquidos - Projeto, construção e operação. Disponível em: <https://http://acquasana.com.br/legislacao/nbr_13969.pdf>. Acesso em: maio de 2020.

Benites, V. M., Madari, B. \& Machado, P. L. O. A. (2003). Extração e fracionamento quantitativo de substâncias húmicas do solo: um procedimento simplificado de baixo custo. Embrapa Solos. Comunicado Técnico, 16, p. 7, Rio de Janeiro (2003).

Bernardes, F. S. (2014). Avaliação do tratamento domiciliar de águas negras por um tanque de evapotranspiração (TEvap). Revista Especialize On-line IPOG,1(7).

BRASIL (2015). Ministério da Saúde. Secretaria de Gestão Estratégica e Participativa. Departamento de Apoio à Gestão Participativa. Saúde e ambiente para as populações do campo, da floresta e das águas / Ministério da Saúde, Secretaria de Gestão Estratégica e Participativa, Departamento de Apoio à Gestão Participativa. - Brasília: Ministério da Saúde, 2015. 216 p. Disponível em:

<http://bvsms.saude.gov.br/bvs/publicacoes/saude_ambiente_populacoes_campo_floresta_ag uas.pdf >. Acesso em: maio de 2020. 
BRASIL (2018). Ministério das Cidades. Secretaria Nacional de Saneamento Ambiental. Sistema Nacional de Informação Sobre Saneamento. Disponível em: http://www.snis.gov.br/ Acesso em: maio de 2020.

Canellas, L. P., Santos, G. A., Rumjanek, V. M., Moraes, A. A. \& Guridi, F. (2001).

Distribuição da matéria orgânica e características de ácidos húmicos em solos com adição de resíduos de origem urbana. Pesquisa Agropecuária Brasileira. 2001.36 (12): 1529-1538. https://doi.org/10.1590/S0100-204X2001001200010.

EMATER (2020). Tanque de evapotranspiração para o tratamento de efluentes do vaso sanitário domiciliar. Disponível em:

<http://www.emater.mg.gov.br/doc/intranet/upload/DETEC_Ambientaltvap_com_defluvio.pd f >. Acesso em: maio de 2020.

Fonseca, J. J. S. (2002). Metodologia da pesquisa científica. Fortaleza: UEC. Apostila.

Galbiati, A. F. (2009). Tratamento domiciliar de águas negras através de tanque de evapotranspiração. Dissertação (mestrado), Campo Grande: Universidade Federal de Mato Grosso do Sul. $38 \mathrm{f}$.

Gerhardt, T. E. \& Silveira, D. T. (2009). Métodos de Pesquisa. Porto Alegre: Editora da UFRGS.

Giddens, A. (2012). Sociologia. Porto Alegre: Artmed, 6. ed.

Gil, A. C. (2007). Como elaborar projetos de pesquisa. São Paulo: Atlas, 4. ed.

INSTITUTO TRATA BRASIL (2018). Esgoto. 2018. Disponível em: $<$ http://www.tratabrasil.org.br/saneamento/principais-estatisticas/no-brasil/esgoto >. Acesso em: maio de 2020. 
Silva Filho, A. V. \& Silva, M. I. V. (2002). Importância das substâncias húmicas para a agricultura. II Simpósio Nacional sobre as Culturas do Inhame e do Taro. João Pessoa-PB. Anais... EMEPA-PB, v.2.

Pires, F. J. (2012). Construção Participativa de Sistemas de Tratamento de Esgoto Doméstico no Assentamento Rural Olga Benário - MG. Dissertação (mestrado), Viçosa: Universidade Federal de Viçosa. $118 \mathrm{f}$.

Tomé Júnior, J. B. (1997). Manual para interpretação de análise de solo. Guaíba: Livraria e Editora Agropecuária. 247 p.

Triviños, A. N. S. (1987). Introdução à pesquisa em ciências sociais: a pesquisa qualitativa em educação. São Paulo: Atlas.

Von Sperling, M. (2005). Introdução à Qualidade das Águas e ao Tratamento de Esgotos Princípios do Tratamento Biológico de Águas Residuárias. Belo Horizonte: DESA-UFMG, v. 1, 3. ed., $452 \mathrm{p}$.

Porcentagem de contribuição de cada autor no manuscrito

Isabela Ribeiro de Sousa Baião - 20\%

Larissa Costa Machado - 20\%

Tamara Daiane de Souza - 20\%

Jaqueline Carla Valamiel de Oliveira e Silva - 20\%

Jussara Aparecida de Oliveira Cotta - 20\% 